\title{
Discrimination in a Low-Wage Labor Market: A Field Experiment
}

\author{
Devah Pager, \\ Princeton University \\ Bruce Western, and \\ Harvard University \\ Bart Bonikowski \\ Princeton University
}

\begin{abstract}
Decades of racial progress have led some researchers and policymakers to doubt that discrimination remains an important cause of economic inequality. To study contemporary discrimination, we conducted a field experiment in the low-wage labor market of New York City, recruiting white, black, and Latino job applicants who were matched on demographic characteristics and interpersonal skills. These applicants were given equivalent résumés and sent to apply in tandem for hundreds of entry-level jobs. Our results show that black applicants were half as likely as equally qualified whites to receive a callback or job offer. In fact, black and Latino applicants with clean backgrounds fared no better than white applicants just released from prison. Additional qualitative evidence from our applicants' experiences further illustrates the multiple points at which employment trajectories can be deflected by various forms of racial bias. These results point to the subtle yet systematic forms of discrimination that continue to shape employment opportunities for low-wage workers.
\end{abstract}

Despite legal bans on discrimination and the liberalization of racial attitudes since the 1960s, racial differences in employment remain among the most enduring forms of economic inequality. Even in the tight labor market of the late 1990s, unemployment rates for black men remained twice that for whites. Racial inequality in total joblessness-including those who exited the labor market-increased among young men during this period (Holzer and Offner 2001). Against this backdrop of persistent racial inequality, the question of employment discrimination has generated renewed interest. Although there is much research on racial disparities in employment, the contemporary relevance of discrimination remains widely contested.

One line of research points to the persistence of prejudice and discrimination as a critical factor shaping contemporary racial disparities (Darity and Mason 1998; Roscigno et al. 2007). A series of studies relying on surveys and in-depth interviews finds that firms are reluctant to hire young minority men — especially blacks—because they are seen as unreliable, dishonest, or lacking in social or cognitive skills (Holzer 1996; Kirschenman and Neckerman 1991; Moss and Tilly 2001; Waldinger and Lichter 2003; Wilson 1996: chap. 5). The strong negative attitudes expressed by employers suggest that race remains highly salient in employers' evaluations of workers. At the same time, research relying on interviews with employers leaves uncertain the degree to which self-reported attitudes are influential in actual hiring decisions (Pager and Quillian 2005). Indeed, Moss and Tilly

Direct all correspondence to Devah Pager, Department of Sociology, Princeton University, Princeton, NJ 08544 pager@ princeton.edu. Reprints: http://www.sagepub.com/journalsReprints.nav 
(2001:151) report the puzzling finding that "businesses where a plurality of managers complained about black motivation are more likely to hire black men." In fact, across a series of analyses controlling for firm size, starting wage, the percent black in the relevant portion of the metropolitan area, and a business's average distance from black residents in the area, Moss and Tilly find that employers who overtly criticize the hard skills or interaction skills of black workers are between two and four times more likely to hire a black worker (pp.151-52). Hiring decisions, of course, are influenced by a complex range of factors, racial attitudes being only one. Employers' stated preferences do not provide a clear picture of the degree to which negative attitudes about blacks translate into active forms of discrimination.

Research focusing on wages rather than employment offers even less evidence of contemporary discrimination. Neal and Johnson (1996), for example, estimate wage differences between white, black, and Latino young men. They find that two thirds of the black-white gap in wages in 1990 to 1991 can be explained by race differences in cognitive test scores measured 11 years earlier, and test scores fully explain wage differences between whites and Latinos. This and similar studies trace the employment problems of young minority men primarily to skill or other individual deficiencies, rather than any direct effect of discrimination (Farkas and Vicknair 1996; Neal and Johnson 1996; O'Neill 1990). Heckman (1998:101-102) puts the point most clearly, writing that "most of the disparity in earnings between blacks and whites in the labor market of the 1990s is due to differences in skills they bring to the market, and not to discrimination within the labor market." He goes on to describe labor market discrimination as "the problem of an earlier era."

Does employer discrimination continue to affect labor market outcomes for minority workers? Clear answers are elusive because discrimination is hard to measure. Without observing actual hiring decisions, it is difficult to assess exactly how and under what conditions race shapes employer behavior. We address this issue with a field experiment that allows direct observation of employer decision making. By presenting equally qualified applicants who differ only by race or ethnicity, we can observe the degree to which racial considerations affect real hiring decisions. Furthermore, we move beyond experimental estimates of discrimination to explore the processes by which discrimination occurs. Examining the interactions between job seekers and employers, we gain new insights into how race influences employers' perceptions of job candidate quality and desirability. Studying the multifaceted character of discrimination highlights the range of decisions that collectively reduce opportunities for minority candidates.

\section{CONCEPTUALIZING DISCRIMINATION}

Empirical studies often portray discrimination as a single decision. Research on employment disparities, for example, considers the role of discrimination at the point of initial hire; research on pay disparities considers discrimination at the point of wage-setting decisions. In reality, discrimination may occur at multiple decision points across the employment relationship. In this way, even relatively small episodes of discrimination-when experienced at multiple intervals or across multiple contexts—can have substantial effects on aggregate outcomes.

Depictions of discriminators also often portray the labor market as divided neatly between employers with a "taste for discrimination" and those who are indifferent to race (Becker 1957). Consequently, it is suggested, job seekers can avoid discrimination by sorting themselves into sectors of the labor market where discrimination is less likely to occur (Heckman 1998:103). Fryer and Levitt (2003:5) characterize employers according to a similar dichotomy, with applicants best advised to identify and avoid employers prone to 
discrimination, rather than wasting time pursuing job opportunities among firms unwilling to hire them: "In the face of discriminatory employers, it is actually in the interest of both employee and employers for Blacks to signal race, either via a name or other résumé information, rather than undertaking a costly interview with little hope of receiving a job offer." According to this conceptualization of labor market discrimination, racial preferences or biases are fixed and concentrated among a specific subset of employers.

Other evidence challenges this tidy distinction between employers who do and do not discriminate. Alternative formulations of labor market discrimination encourage us to view the process as more interactive, contextual, and widespread. Theories of both statistical discrimination and stereotypes view race as a heuristic employers use to evaluate job applicants about whom little is known. Here, group-based generalizations provide guidance about the expected profile of individuals from a given group and facilitate decision making when information or time are scarce (Aigner and Cain 1977; Fiske 1998). Heuristics of this kind are pervasive (and often unconscious). Their effects may vary depending on the availability of and attention to person-specific information (such as that conveyed through application materials or in an interview) that may interact with and potentially override initial expectations.

A long line of social psychological research investigates how stereotypes give way to individualizing information, as well as the conditions under which stereotypes demonstrate a stubborn resistance to change (Bodenhausen 1988; Fiske 1998; Trope and Thomson 1997). ${ }^{1}$ This research suggests that salient personalizing information can quickly counteract stereotyped expectations; however, in evaluating difficult-to-observe or ambiguously relevant characteristics, or when decision makers have competing demands on their attention, stereotypes often filter information in ways that preserve expectations (Darley and Gross 1983; Dovidio and Gaertner 2000; Gilbert and Hixon 1991). In these cases of decision making under uncertainty, racial preferences or biases are unlikely to be expressed in any static or uniform way, but will vary in intensity and consequence depending on other characteristics of the applicant, the employer, and the interaction between the two.

In addition to noting the varying role of race across employment interactions, some research shifts the focus from employer characteristics to the characteristics of the job for which a given worker is being considered. Previous research points to the negative consequences of the changing composition of low-wage jobs for black men, with the shift from manufacturing to services skewing the distribution of skill demands toward "soft skills," for which black men are considered lacking (Moss and Tilly 2001). Jobs involving customer service or contact with clients heighten the salience of race because of employers' concerns about the dress and demeanor of young black men (Moss and Tilly 2001). Jobs at the "back of the house" or those emphasizing manual skills are less likely to activate concerns of this kind. In this scenario, discrimination may obtain not at the employer level but at the job level, with black applicants excluded from some job types and channeled into others. In this case, we would look to variation in discrimination not among employers but among the job openings for which workers are being considered.

Rather than viewing discrimination as a single decision, or as the result of a small group of highly prejudiced employers, a growing body of research points to the variable contexts that shape how information about applicants may be filtered and interpreted along racial lines. Decision making under uncertainty and the race-typing of jobs both make discrimination more likely. To capture the contingent and cumulative effects of discrimination implied by

\footnotetext{
1 Theories of statistical discrimination also predict employer responsiveness to individual characteristics (e.g., Altonji and Pierret 2001; Oettinger 1996; cf.Pager and Karafin 2009).
} 
these theories requires an examination of how experiences of discrimination may be distributed across a wide range of decision points and may vary depending on interactions among the employer, the applicant, and the job in question.

\section{THE CHANGING LANDSCAPE OF LOW-WAGE LABOR MARKETS}

Economic theory predicts the decline of discrimination through market competition (Becker 1957), but several features of contemporary low-wage labor markets may sustain or renew racialized decision making. Shifts in the composition of both low-wage jobs and workers have potentially created new incentives and opportunities for employers to enact racial preferences in hiring. First, low-wage job growth is concentrated in service industries, in positions that place a heavy emphasis on self-presentation, interaction with customers, and other personality-related attributes (Moss and Tilly 2001). As discussed earlier, employers consistently express concerns over the "soft skills" of black men, implying a potential skills mismatch between the skill requirements of new job growth and the perceived skill profile of black male job seekers. Furthermore, because many of the qualities valued by employers for contemporary low-wage jobs are difficult to evaluate from a written application or brief meeting, generalized negative perceptions of minority workers may be more difficult for individual minority applicants to disconfirm (Biernat and Kobrynowicz 1997).

Second, low-wage labor markets today are characterized by increasing heterogeneity of the urban minority work force, with low-skill black workers now more likely to compete with other minority groups-in particular, low-skill Latino workers. Interviews with employers in Los Angeles and Chicago suggest consistent preferences for Latinos over blacks, with Latino workers viewed as more pliant, reliable, and hard-working (Kirschenman and Neckerman 1991; Waldinger and Lichter 2003). Given these racial preferences among employers, growing competition within the low-wage labor market may leave black men vulnerable to discrimination relative not only to whites, but to Latinos as well.

Finally, low-wage labor markets are increasingly supplied by workers with criminal records. Nearly a third of black men without a college degree have prison records by their mid-30s, adding to employers' reservations about black male job applicants (Pager 2007b; Pettit and Western 2004). The high rate of incarceration makes a criminal record a newly important source of stigma that is worth studying in its own right. Moreover, we can view a criminal record as an extreme and authoritative signal of the kinds of problematic behaviors that employers ascribe to young black men. In this context, separating the effects of criminal stigma from race provides a useful benchmark for measuring racial stigma. In the first effort in this direction, Pager's (2003) research in a Milwaukee field experiment compared racial and criminal stigma among matched pairs of job seekers. Fielding a pair of black and a pair of white job applicants (in which one member of each pair was randomly assigned a criminal record), Pager found that a black applicant with no criminal background experiences job prospects similar to those of a white felon. That blackness confers the same disadvantage as a felony conviction helps calibrate the deeply skeptical view of young black men in the eyes of Milwaukee employers.

The growing importance of soft skills, ethnic heterogeneity, and job seekers with criminal records suggest the persistence or increasing incidence of discrimination in contemporary low-wage labor markets. Whether based on statistical generalizations or inaccurate stereotypes, preconceived notions about the characteristics or desirability of black men relative to other applicant types are likely to structure the distribution of opportunity along racial lines. 


\section{METHODS FOR STUDYING LABOR MARKET DISCRIMINATION}

Racial discrimination in the labor market is typically studied by comparing the wages of whites and minorities, statistically controlling for human capital characteristics. Estimates from a variety of social surveys suggest that the black-white difference in hourly wages among men usually range between about 10 and 20 percent (Cancio, Evans, and Maume 1996; Darity and Meyers 1998; Neal and Johnson 1996). Although widely used, this residual method, in which discrimination is defined as the unexplained race difference in wages, is sensitive to the measurement of human capital. Where race differences in human capital are incompletely observed, the effect of discrimination may be overestimated (Farkas and Vicknair 1996; Neal and Johnson 1996).

Residual estimates of discrimination infer employer behavior from data on workers' wages. Field experiments, by contrast, offer a more direct approach to the measurement of discrimination. This approach, also referred to as an audit methodology, involves the use of matched teams of job applicants - called testers-who apply to real job openings and record responses from employers. Testers are assigned equivalent résumés and are matched on a variety of characteristics like age, education, physical appearance, and interpersonal skills. Because black and white testers are sent to the same firms, and testers are matched on a wide variety of characteristics, much of the unexplained variation that confounds residual estimates of discrimination is experimentally controlled.

In part due to taxing logistical requirements, the use of in-person audit studies of employment remains rare, with only a handful of such studies conducted over the past 20 years (Bendick, Jackson, and Reinoso 1994; Bendick et al. 1991; Cross et al. 1990; Pager 2003; Turner, Fix, and Struyk 1991). ${ }^{2}$ Moreover, the typical emphasis on a single comparison group leaves several significant features of contemporary urban labor markets unexplored.

By studying both race and criminal background, the Milwaukee audit study represents an important starting point for this project (Pager 2003). The Milwaukee study examined the influence of the criminal justice system on labor market stratification by studying the effect of a criminal record for black and white job seekers. Although race emerged as a key theme in the study's findings, the topic of racial discrimination was not a central focus. Moreover, the research design yielded only indirect evidence of racial discrimination because black and white testers did not apply to the same employers. Our ability to investigate when and how racial discrimination occurs is therefore limited in this context.

The current study updates and extends earlier research in several ways. First, we focus directly on the question of racial discrimination, in both conceptualization and design. This emphasis allows us to situate our research within ongoing debates about discrimination and to provide a rigorous design for detecting racial discrimination. Second, we move beyond standard two-race models of discrimination by including matched black, white, and Latino job seekers, reflecting the racial heterogeneity of large urban labor markets. To our knowledge, this is the first study of its kind to simultaneously examine the employment experiences of three racial/ethnic groups. Third, to help calibrate the magnitude of racial preferences, we compare applicants affected by varying forms of stigma; specifically, we compare minority applicants with white applicants just released from prison. Where the Milwaukee study attempted this comparison across teams, the present analysis provides a

\footnotetext{
${ }^{2}$ For a summary of the results of earlier audit studies of employment, see Heckman and Siegelman (1993) and Pager (2007a). Correspondence studies, which rely on résumés sent by mail rather than in-person applications (e.g., Bertrand and Mullainathan 2004), are less costly but rely on application procedures less suited for low-wage labor markets (which typically require in-person applications)
} 
direct test by comparing the outcomes of minority and ex-offender applicants who visit the same employers. Finally, we extend our analysis from the quantitative evidence of differential treatment to a rich set of qualitative data that allow for an exploration of the process of discrimination. Drawing from the testers' extensive field notes that describe their interactions with employers, we provide a unique window into the range of employer responses that characterize discrimination in contemporary low-wage labor markets.

\section{RESEARCH DESIGN AND METHODS}

The New York City Hiring Discrimination Study sent matched teams of testers to apply for 340 real entry-level jobs throughout New York City over nine months in 2004. The testers were well-spoken, clean-cut young men, ages 22 to 26. Most were college-educated, between 5 feet 10 inches and 6 feet in height, and recruited in and around New York City. They were matched on the basis of their verbal skills, interactional styles (level of eye contact, demeanor, and verbosity), and physical attractiveness. Testers were assigned fictitious résumés indicating identical educational attainment and comparable qualities of high school, work experience (quantity and kind), and neighborhood of residence. Résumés were prepared in different fonts and formats and randomly varied across testers, with each résumé used by testers from each race group. Testers presented themselves as high school graduates with steady work experience in entry-level jobs. Finally, the testers passed a common training program to ensure uniform behavior in job interviews. While in the field, the testers dressed similarly and communicated with teammates by cell phone to anticipate unusual interview situations.

We fielded two teams that each included a white, Latino, and black tester. To help ensure comparability, the Latino testers spoke in unaccented English, were U.S. citizens of Puerto Rican descent, and, like the other testers, claimed no Spanish language ability. The first team tests a standard racial hierarchy, with the white tester serving as a benchmark against which to measure variation in racial and ethnic discrimination. To calibrate the magnitude of racial stigma, the second team compares black and Latino testers with a white tester with a criminal record. The criminal record was typically disclosed in answer to the standard question on employment applications, "Have you ever been convicted of a crime? If yes, please explain." We instructed testers to reveal, when asked, that they had recently been released from prison after serving 18 months for a drug felony (possession with intent to distribute, cocaine). In addition, following Pager (2003), the white tester's criminal record was also signaled on the résumé by listing work experience at a state prison and by listing a parole officer as a reference. ${ }^{3}$

For both teams, we sampled employers from job listings for entry-level positions, defined as jobs requiring little previous experience and no more than a high school degree. Job titles included restaurant jobs, retail sales, warehouse workers, couriers, telemarketers, customer service positions, clerical workers, stockers, movers, delivery drivers, and a wide range of other low-wage positions. Each week, we randomly drew job listings from the classified sections of the New York Times, Daily News, New York Post, Village Voice, and the online service Craigslist. The broad range of job listings allowed for extensive coverage of the entry-level labor market in New York. From the available population of job listings, we took a simple random sample of advertisements each week. Testers in each team applied to each job within a 24-hour period, randomly varying the order of the applicants.

\footnotetext{
${ }^{3}$ Results from Pager (2003) suggest that providing information about a criminal record to employers who do not request the information does little to affect hiring decisions.
} 
Our dependent variable records any positive response in which a tester was either offered a job or called back for a second interview. We recorded callbacks using voicemail boxes set up for each tester. For employer $i(i=1, \ldots, N)$ and tester $t(t=W, B$, or $L$ for white, black, or Latino), a positive response, $y_{i t}$, is a binary variable that scores 1 for a job offer or callback, and 0 otherwise. We define the level of differential treatment as the ratio in positive response rates for each comparison, $r_{W B}=\bar{y}_{W} / \bar{y}_{B}$, where $\bar{y}_{t}$ is the proportion of positive responses for testers of race $t$. Under the null hypothesis of equal treatment, $r_{W B}=$ 1 , the proportion of positive responses received by each racial group is equal. For data on matched pairs, several statistical tests have been proposed that use within-pair comparisons to account for the correlation of observations from the same pair (e.g., Agresti 1990; Heckman and Siegelman 1993). In our case, where three testers are sent to the same employer, we have a matched triplet and information from all three testers should ideally contribute to an inference about a contrast between any two. Ghosh and colleagues (2000) suggest that matched pairs can be fit with a hierarchical logistic regression with a random effect for each pair. We generalize their approach to our matched triplets, fitting a random effect for each employer. If the probability of a positive response is given by $\mathrm{E}\left(y_{i t}\right)=p_{i}$, the hierarchical model is written

$$
\log \left(\frac{p_{i t}}{1-p_{i t}}\right)=\alpha_{i}+\beta B_{i t}+\gamma L_{i t}
$$

where $B_{i t}$ is a dummy variable for blacks, $L_{i t}$ is a dummy variable for Latinos, and the random effects for employers, $\alpha_{\mathrm{i}}$, is given a normal distribution. The employer effects, $\alpha_{\mathrm{i}}$, induce a correlation among observations from the same employers and reduce standard errors, as in the usual matched-pair inference. We estimate the models with Markov Chain Monte Carlo methods. We construct intervals for the ratios $\left({ }_{r W B}, r_{W L}\right.$, and $\left.r_{B L}\right)$ by taking random draws from the posterior predictive distribution of $y_{i t}$. Alternative methods that adjust for clustering by employer yield similar results to those reported below.

\section{THE PROBLEMS OF MATCHING}

The quality of audit results depends on the comparability of the testers. Because race cannot be experimentally assigned, researchers must rely on effective selection and matching to construct audit teams in which all relevant characteristics of testers are similar-something that may leave substantial room for bias. Heckman and Siegelman (1993) argue that researchers know little about the hard-to-observe characteristics highly prized by employers. If testers are poorly matched, evidence of discrimination may be merely an artifact of idiosyncratic tester characteristics.

Bertrand and Mullainathan (2004) remove tester effects in a "correspondence test" that sent résumés with common white and black names to employers in Boston and Chicago. Their design allows the random assignment of résumé characteristics to white- and black-sounding names, largely removing concerns about unobserved characteristics. Résumés with white names were 50 percent more likely than those with black names to receive callbacks from employers ( 9.7 versus 6.5 percent). Studies of this kind provide some reassurance that results from the body of audit research are not driven by tester effects alone.

Because we rely on in-person audits for our study of low-wage labor markets, the effective matching of testers is a key concern. ${ }^{4}$ We reviewed more than 300 applicants to identify our final team of 10 testers. ${ }^{5}$ Successful applicants were subject to two lengthy screening interviews and a written test, a far more probing job selection process than the testers encountered in their fieldwork. ${ }^{6}$ Each tester passed a standard training period, was required to dress uniformly, and was subject to periodic spot checks for quality control. ${ }^{7}$ 
Despite these measures, uncontrolled tester effects remain a threat to inferences about discrimination. We assess the sensitivity of our results to testers in four ways. First, each tester may have a unique effect, but the average effect of the testers may be zero. In this case, the observations from each tester will be correlated and standard errors that ignore this clustering will tend to be too small. We allow for this possibility by fitting an additional random effect for each tester in our hierarchical logistic regression. ${ }^{8}$ Second, each tester may have a unique effect, but these effects may not average to zero. To assess the sensitivity of our results to each tester, we perform a type of cross-validation in which the treatment effect is recalculated for a reduced data set, sequentially omitting those employers associated with each individual tester. Confidence intervals below are based on models that include employer and tester random effects. We compare these results with cross-validation treatment effects based on subsets of the data in which individual testers are sequentially omitted. Third, we recalculate our key results for each unique combination of testers matched in teams over the course of the fieldwork (see Appendix Table A2). These results, although sensitive to small sample sizes for some combinations, tend to support the consistency of effects across a number of tester comparisons.

As a final investigation of tester effects, we consider the possibility that the expectations or behaviors of testers may influence the audit results in nonrandom ways. For example, if a black tester expects to be treated poorly by employers, he may appear more withdrawn, nervous, or defensive in interactions. The nature of the interaction may create a selffulfilling prophecy, in which the tester experiences poor outcomes for reasons unrelated to his race (Steele and Aronsen 1995). We assess these tester effects by analyzing the degree to which personal contact between testers and employers is associated with widening racial disparities. Overall, we find no evidence that testers' interpersonal styles or expectations are associated with increasing discrimination; if anything, personal contact appears to weaken the effect of race, suggesting that testers' performance minimized, rather than exaggerated, our measures of racial bias (see Appendix, Table A1).

The problem of imperfect matching among testers is a well-understood vulnerability of audit experiments, and one to which we devoted considerable attention. Ironically, however, achieving perfect matches can itself produce distortions in the hiring process. Because audit partners are matched on all characteristics that are most directly relevant to hiring decisions (e.g., education, work experience, and physical attributes), employers may be forced to privilege relatively minor characteristics simply out of necessity to break a tie (Heckman 1998:111). If employers care only marginally about race, but are confronted with applicants equal on all other dimensions, this single characteristic may take on greater significance than it would under normal circumstances when evaluating real applicants who differ according to multiple dimensions.

\footnotetext{
${ }^{4}$ In-person audits also allow for the inclusion of a wide range of entry-level job types (which often require in-person applications); they provide a clear method for signaling race, without concerns over the class-connotations of racially distinctive names (Fryer and Levitt 2004); and they allow us to gather both quantitative and qualitative data, with information on whether an applicant receives the job as well as how he is treated during the interview process.

${ }_{5}^{5}$ These 300 applicants were prescreened for appropriate age, race, ethnicity, and gender.

${ }^{6}$ Indeed, as an employer herself, the researcher must identify subtle cues about applicants that indicate their ability to perform. Whether or not these cues are explicit, conscious, or measurable, they are present in a researcher's evaluation of tester candidates, just as they are in employers' evaluations of entry-level job applicants. Like employers, researchers are affected by both objective and subjective/subconscious indicators of applicant quality in their selection and matching of testers in ways that should ultimately improve the nuanced calibration of test partners.

${ }^{7}$ In addition to on-site supervision at the start and finish of each day of fieldwork, on several occasions, we "tested the testers." For example, we hid video cameras in the offices of confederate employers, which allowed us to monitor testers' compliance with the audit protocol as well as to use the tapes as a training tool to better synchronize test partners' performance (not counted among results).

${ }^{8}$ Additional models (not shown here) test for fixed effects of individual testers; we find no significant differences across testers within each race group.
} 
The design of our study, which focuses on the early stages of the hiring process, avoids situations in which employers must choose only a single applicant. By using "callbacks" as one of our key dependent variables, we include cases that represent an employer's first pass at applicant screening. ${ }^{9}$ Indeed, recent surveys suggest that employers interview an average of six to eight applicants for each entry-level job opening (Pager 2007b). If race represents only a minor concern for employers, we would expect all members of our audit team to make it through the first cut. If race figures prominently in the first round of review, we can infer that this characteristic has been invoked as more than a mere tie-breaker. In these cases, the evidence of race-based decision making is quite strong.

\section{EXPERIMENTAL RESULTS}

The primary results from the field experiment focus on the proportion of applications submitted by testers that elicited either a callback or a job offer from employers, by race of the applicant. Our first team assesses the effects of race discrimination by comparing the outcomes of equally qualified white, Latino, and black applicants. Figure 1a reports positive response rates for each racial/ethnic group. In applications to 171 employers, the white tester received a callback or job offer 31.0 percent of the time, compared with a positive response rate of 25.2 percent for Latinos and 15.2 percent for blacks. These results show a clear racial hierarchy, with whites in the lead, followed by Latinos, and blacks trailing behind.

Figure $1 \mathrm{~b}$ shows the contrasts between the three race groups. Once we adjust for employer and tester effects, the confidence interval for the white-Latino ratio of 1.23 includes one. ${ }^{10}$ By contrast, the white-black ratio of 2.04 is substantively large and statistically significant. The positive response rate for blacks is also significantly lower than the rate for Latinos. The points in the figure show the cross-validation results obtained by sequentially dropping cases associated with each individual tester. All ratios remain consistently greater than one, indicating that employers treat blacks less positively regardless of which testers are applying for jobs. Overall, these results indicate that, relative to equally qualified blacks, employers significantly prefer white and Latino job applicants. The findings suggest that a black applicant has to search twice as long as an equally qualified white applicant before receiving a callback or job offer from an employer.

The results from this first comparison indicate employers' strong racial preferences, but the magnitude of this preference remains some-what abstract. To calibrate the effects of race against another stigmatized category, the ex-offender, we repeated the experiment, this time assigning a criminal record to the white tester. Figure 2 a shows the percentage of positive responses-job offers or callbacks-received by each tester. In this experiment, whites with criminal records obtained positive responses in 17.2 percent of 169 job applications, compared with 15.4 percent for Latinos and 13.0 percent for blacks. ${ }^{11}$ The white testers' racial advantage narrows substantially in this comparison; yet the white applicant with a criminal record still does just as well, if not better, than his minority counterparts with no criminal background.

\footnotetext{
${ }^{9}$ Positive responses recorded in this study were fairly evenly split between callbacks and job offers. Employers who made offers onthe-spot were typically hiring more than one applicant, thus similarly avoiding a situation in which a forced-choice becomes necessary. In fact, rates of job offers were more evenly distributed by race relative to callbacks (see Tables A1 and A2).

${ }^{10}$ In a model pooling cases from the two teams, with main effects for team and criminal background, the white-Latino gap becomes statistically significant. The generality of this result certainly deserves more study. The Puerto Ricans of New York that our Latino testers represent are a longstanding community of U.S. citizens. In other local labor markets, where markers of citizenship and accent are more prominent sources of difference, evidence of ethnic discrimination may be stronger.

${ }^{11}$ The overall rate of positive responses is lower for all testers relative to the results presented in Figure 1. This is likely due to the staggered fielding of teams and resulting differences in the composition of employers audited across the two time periods.
} 
Figure $2 b$ shows that the white-Latino ratio is close to one and the confidence interval overlaps one by a large margin. The white-black ratio is now a statistically insignificant 1.32 , compared with a significant ratio of 2.04 when the white tester had a clean record. As in the previous experiment, Latinos were preferred to blacks, but here the difference is not significant. As before, the cross-validation treatment effects, obtained by dropping employers associated with one particular tester, are all close to one. These results indicate that, regardless of which testers were sent into the field, employers differentiated little among the three applicant groups.

The comparison of a white felon with black and Latino applicants with clean backgrounds provides a vivid calibration of the effects of race on hiring decisions. While ex-offenders are disadvantaged in the labor market relative to applicants with no criminal background, the stigma of a felony conviction appears to be no greater than that of minority status. Replicating earlier results from Milwaukee (Pager 2003), these findings suggest that New York employers view minority applicants as essentially equivalent to whites just out of prison.

Theories of statistical discrimination point to the very high incarceration rates among young black men as a key explanation for employers' indifference between white felons and blacks with potentially unobserved criminal histories. Current estimates suggest that roughly 18 percent of young black men with high school degrees will experience incarceration by their early 30s (Pettit and Western 2004), and a larger fraction surely have lower level convictions and arrests. Still, the fact that known information about a white applicant's serious criminal conviction is viewed with no more concern than the assumed characteristics of a young black man points to the strength and intensity of contemporary racial attitudes. Overcoming these negative expectations, even for a candidate with otherwise appealing characteristics, requires the negotiation of a number of significant hurdles not present for white job seekers.

\section{RACE AT WORK: AN EXAMINATION OF INTERACTIONS BETWEEN APPLICANTS AND EMPLOYERS}

The strong evidence of hiring discrimination from the field experiment provides a clear measure of the continuing significance of race in employer decision making. These numbers, however, tell us little about the process by which race comes to matter. Fortunately, the in-person design of the experiment allows us to further supplement the experimental findings with qualitative evidence from testers' field notes that report their interactions in job interviews. These detailed narratives describe employers' deliberations and suggest some of the ways race comes into play during employment interactions.

Our analysis examines cases in which testers had sufficient interaction with employers for content coding. Consistent with the notion that contemporary forms of discrimination are largely subtle and covert, many cases contain little that would lead us to anticipate the differential treatment that followed. Of those that do, however, we observe several consistent patterns in employers' responses. In particular, three categories of behavior stand out, which we refer to here as: categorical exclusion, shifting standards, and race-coded job channeling. The first type of behavior, categorical exclusion, is characterized by an immediate or automatic rejection of the black (or minority) candidate in favor of a white applicant. Occurring early in the application process, these decisions involve little negotiated interaction but appear to reflect a fairly rigid application of employers' racial preferences or beliefs. A second category of behavior, shifting standards, reflects a more dynamic process of decision making. Here we observe cases in which employers' evaluations of applicants appear actively shaped or constructed through a racial lens, with similar qualifications or deficits taking on varying relevance depending on an applicant's race. Finally, a third category of behavior moves beyond the hiring decision to a focus on job placement. Race- 
based job channeling represents a process by which minority applicants are steered toward particular job types, often those characterized by greater physical demands and reduced customer contact.

By observing the interactions that characterize each of these behavior types, we gain a rare glimpse into the processes by which discrimination takes place. At the same time, we emphasize that this discussion is intended as a descriptive exercise rather than a formal causal analysis. Indeed, the categories we identify are not mutually exclusive; some of the same processes may be operating simultaneously, with employers' shifting evaluations of applicant skills leading to different patterns of job channeling, or assumptions about the appropriate race of the incumbent of a particular position leading to forms of categorical exclusion. Likewise, this typology cannot account for all of the differential treatment we observe-at least half of the employer decisions were made on the basis of little or no personal contact between applicant and employer, leaving the nature of the decision entirely unobserved. With these caveats in mind, we nevertheless view the analysis as providing a unique contribution to the study of racial discrimination, revealing mechanisms at work that observational research can rarely identify.

\section{CATEGORICAL EXCLUSION}

Few interactions between our testers and employers revealed signs of racial animus or hostility toward minority applicants. At the same time, a close comparison of test partners' experiences shows a number of cases in which race appears to be the sole or primary criterion for an employer's decision. With little negotiation or deliberation over the selection decision, these employers' decisions seem to reflect a preexisting judgment regarding the adequacy or desirability of a minority candidate. The uncompromising nature of the employer's decision can be characterized as a form of categorical exclusion.

A clear-cut case of categorical exclusion was provided when all three testers applied for a warehouse worker position and received a perfunctory decision. Zuri, one of our black testers, reported: "The original woman who had herded us in told us that when we finished filling out the application we could leave because 'there's no interview today, guys!' ... When I made it across the street to the bus stop ... the woman who had collected our completed applications pointed in the direction of Simon, Josue, and myself [the three test partners] motioning for us to return. All three of us went over.... She looked at me and told me she 'needed to speak to these two' and that I could go back." Zuri returned to the bus stop, while his white and Latino test partners were both asked to come back at 5 p.m. that day to start work. Simon, the white tester, reported, "She said she told the other people that we needed to sign something - that that's why she called us over—so as not to let them know she was hiring us. She seemed pretty concerned with not letting anyone else know."

In this context, with no interview and virtually no direct contact with the employer, we observe a decision that appears to be based on little other than race. The job is a manual position for which Zuri is at least as able, yet he is readily passed over in favor of his white and Latino counterparts.

This case is unusual in that three testers were rarely present at a given location at the same time. More often, we found evidence of differential treatment only after comparing the testers' reports side by side. Here again, we observed several hiring decisions in which race appeared to be the sole or primary source of differentiation. In one example, the three testers inquired about a sales position at a retail clothing store. Joe, one of our black testers, reported that, "[the employer] said the position was just filled and that she would be calling people in for an interview if the person doesn't work out." Josue, his Latino test partner, was told something very similar: "She informed me that the position was already filled, but did 
not know if the hired employee would work out. She told me to leave my résumé with her." By contrast, Simon, their white test partner, who applied last, had a notably different experience: "I asked what the hiring process was-if they're taking applications now, interviewing, etc. She looked at my application. 'You can start immediately?'Yes. 'Can you start tomorrow?'Yes. '10 a.m.' She was very friendly and introduced me to another woman (white, 28) at the cash register who will be training me."

A similar case arose a few weeks later at an electronics store. Joe, the black tester, was allowed to complete an application but was told that his references would have to be checked before he could be interviewed. Meanwhile, Simon and Josue, his white and Latino partners, applied shortly afterward and were interviewed on the spot. Joe's references were never called, while Simon received a callback two days later offering him the job.

When evaluated individually, these interactions do not indicate racial prejudice or discrimination. Side by side, however, we see that minority applicants encounter barriers not present for the white applicant, with employers citing excuses for putting off the black or minority candidate (e.g., "the job has already been filled" or "we'd have to check your references before we can proceed") that appear not to apply for the white applicant. To be sure, certain cases may capture random error-perhaps a position became available between the testers' visits, or an employer was otherwise preoccupied when one applicant arrived but not another, leading to the employer's differential response. Still, the consistency of the pattern in these data suggests that random error is unlikely to be a dominant factor. Indeed, of the 171 tests conducted by the first team (no criminal background), white testers were singled out for callbacks or job offers 15 times, whereas there was only a single case in which a black tester received a positive response when his white or Latino partner did not. ${ }^{12}$

These cases of categorical exclusion, although directly observed in only a small number of audits ( 5 of the 47 cases of differential treatment across the two teams), reveal one form of discrimination in which racial considerations appear relatively fixed and unyielding. 13 Before black (or minority) candidates have the chance to demonstrate their qualifications, they are weeded out on the basis of a single categorical distinction.

Categorical exclusion represents one important form of discrimination. While these rather abrupt interactions reveal little about the underlying motivation that drives employers' decisions, they do demonstrate the sometimes rigid barriers facing minority job seekers. In these cases, black (or minority) applicants are discouraged or dismissed at the outset of the employment process, leaving little opportunity for a more nuanced review.

\section{SHIFTING STANDARDS}

Making it past the initial point of contact was not the only hurdle facing minority applicants. Indeed, among those who recorded more extensive interaction with employers, we observe a complex set of racial dynamics at work. On the one hand, personal contact with employers was associated with significantly improved outcomes for all testers and a narrowing of the racial gap (see Appendix, Table A1). The testers' interpersonal skills seemed to reduce the influence of racial bias, or at least did not exacerbate it. Yet, even in the context of this more personalized review, we see evidence of subtle bias in the evaluation of applicant

\footnotetext{
12 In an additional 13 cases, both white and Latino testers received positive responses; in seven cases, the Latino tester alone was selected (see Appendix, Table A2).

${ }^{13}$ The denominator of 47 represents the total number of cases of black-white differential treatment from the first $(\mathrm{N}=28)$ and second $(\mathrm{N}=19)$ teams. In calculating the numerator, we do not include a number of additional cases of differential treatment resulting from applications in which there was little or no personal contact between testers and the employer (rates of personal contact were similar by race of tester). In such cases, differential treatment may reflect categorical exclusion (based on a visual assessment of the candidate), shifting standards (based on a review of the completed applications), random error, or something else.
} 
qualifications. In particular, a number of cases reveal how testers' "objective" qualifications appear to be reinterpreted through the lens of race. Although testers' résumés were matched on education and work experience, some employers seemed to weigh qualifications differently depending on the applicant's race. In the following interactions, we see evidence that the same deficiencies of skill or experience appear to be more disqualifying for the minority job seekers $(\mathrm{N}=11)$.

In one case, Joe, a black tester, was not allowed to apply for a sales position due to his lack of direct experience. He reported, "[The employer] handed me back my résumé and told me they didn't have any positions to offer me ... that I needed a couple years of experience." The employer voiced similar concerns with Josue and Kevin, Joe's Latino and white partners. Josue wrote, "After a few minutes of waiting ... I met with [the employer] who looked over my résumé. He said that he was a little worried that I would not be able to do the work." Kevin reported an even stronger reaction: "[The employer] looked at my résumé and said, 'There is absolutely nothing here that qualifies you for this position." Yet, despite their evident lack of qualifications, Kevin and Josue were offered the sales job and asked to come back the next morning. In interactions with all three testers, the employer clearly expressed his concern over the applicants' lack of relevant work experience. This lack of experience was not grounds for disqualification for the white and Latino candidates, whereas the black applicant was readily dismissed.

When applying for a job as a line cook at a midlevel Manhattan restaurant, the three testers encountered similar concerns about their lack of relevant experience. Josue, the Latino tester, reported, "[The employer] then asked me if I had any prior kitchen or cooking experience. I told him that I did not really have any, but that I worked alongside cooks at [my prior job as a server]. He then asked me if I had any 'knife' experience and I told him no.... He told me he would give me a try and wanted to know if I was available this coming Sunday at 2 p.m." Simon, his white test partner, was also invited to come back for a trial period. By contrast, Joe, the black tester, found that "they are only looking for experienced line cooks." Joe wrote, "I started to try and convince him to give me a chance but he cut me off and said I didn't qualify." None of the testers had direct experience with kitchen work, but the white and Latino applicants were viewed as viable prospects while the black applicant was rejected because he lacked experience.

In other cases, employers perceived real skill or experience differences among applicants despite the fact that the testers' résumés were designed to convey identical qualifications. In one example, the testers applied for a job at a moving company. Joe, the black applicant, spoke with the employer about his prior experience as a stockperson at a moving truck company, but "[the employer] told me that he couldn't use me because he is looking for someone with moving experience." Josue, his Latino partner, presented his experience as a stocker at a delivery company and reported a similar reaction, "He then told me that since I have no experience ... there is nothing he could do for me." Simon, their white test partner, presented identical qualifications, but the employer responded more favorably: “"To be honest, we're looking for someone with specific moving experience. But because you've worked for [a storage company], that has a little to do with moving.' He wanted me to come in tomorrow between 10 and 11." The employer is consistent in his preference for workers with relevant prior experience, but he is willing to apply a more flexible, inclusive standard in evaluating the experience of the white candidate than in the case of the minority applicants. Employers' shifting standards, offering more latitude to marginally skilled white applicants than to similarly qualified minorities, suggest that even the evaluation of "objective" information can be affected by underlying racial considerations. 
Even in cases where the white tester presented as a felon, we see some evidence that this applicant was afforded the benefit of the doubt in ways that his minority counterparts were not. In applying at an auto dealership, for example, the three testers met with very different reactions. Joe, the black tester, was informed at the outset that the only available positions were for people with direct auto sales experience. When Josue, his Latino partner, applied, the lack of direct auto sales experience was less of a problem. Josue reported, "He asked me if I had any customer service experience and I said not really... He then told me that he wanted to get rid of a few bad apples who were not performing well. He asked me when I could start." Josue was told to wait for a callback on Monday. When the employer interviewed Keith, their white exfelon test partner, he gave him a stern lecture regarding his criminal background. The employer warned, "I have no problem with your conviction, it doesn't bother me. But if I find out money is missing or you're not clean or not showing up on time I have no problem ending the relationship." Despite the employer's concerns, Keith was offered the job on the spot. The benefit of the doubt conferred by whiteness persists here, even in the context of a white applicant just released from prison.

A pattern in these interactions, when compared side by side, is the use of double standardsseeking higher qualifications from blacks than non-blacks, or viewing whites as more qualified than minorities who present equivalent résumés. Recent research emphasizes employers' use of race as a proxy for difficult-to-observe productivity characteristics (Moss and Tilly 2001; Waldinger and Lichter 2003). Where we have detailed field notes on job interviews, the interactions we observe suggest that employers also use race in interpreting and weighing observable skill characteristics. Standards appear to shift as employers evaluate various applicants' qualifications differently depending on their race or ethnicity (see also Biernat and Kobrynowicz 1997; Yarkin, Town, and Wallston 1982).

\section{RACE-CODED JOB CHANNELING}

The first two categories of differential treatment focus on the decision to hire. Beyond this binary decision, employers also face decisions about where to place a worker within the organizational hierarchy. Here, at the point of job placement, we observe a third category of differential treatment. In our review of the testers' experiences, we noticed that applicants were sometimes encouraged to apply for different jobs than the ones initially advertised or about which they had inquired. In many cases, these instances of channeling suggest a racecoding of job types, whereby employers prefer whites for certain positions and minorities for others. In one case, Zuri, a black tester, applied for a sales position at a lighting store that had a sign in the front window stating "Salesperson Wanted." Zuri described the following interaction: "When she asked what position I was looking for I said I was open, but that since they were looking for a salesperson I would be interested in that. She smiled, put her head in her hand and her elbow on the table and said, 'I need a stock boy. Can you do stock boy?"' Zuri's white and Latino test partners, by contrast, were each able to apply for the advertised sales position.

Another black tester, Joe, was similarly channeled out of a customer service position in his application to a Japanese restaurant. Joe reported, "I told her I was there to apply for the waiter position and she told me that there were no server positions. I told her it was advertised in the paper, and she said there must have been a mistake. She said all she had available was a busboy position. I told her since there was no waiter position, I would apply for the busboy." Later that day, Kevin, his white test partner, was hired for the server position on the spot.

We also observed channeling of the Latino testers. Josue's fieldnotes of an audit at a clothing retailer begin by describing the "young white 20-something women running the place." One of the women interviewed him, asked about past work experience, and asked 
which job he was applying for. "I told her 'sales associate," Josue reported, and he presented a résumé on which the most recent job listed was as a sales assistant at a sporting goods store. "She then told me that there was a stock position and asked if I would be interested in that." Josue was offered the stocker job and asked to start the next day.

In many cases, these instances of channeling are coded as "positive responses" in the initial analyses. While our key concern is about access to employment of any kind, this general focus masks another form of racial bias at work. A closer analysis of the testers' experiences suggests that decisions about job placement, like hiring more generally, often follow a racial logic. We coded all instances of job channeling across both our teams and counted 53 cases (compared with 172 positive responses). By comparing the original job title to the suggested job type, we then categorized these cases as downward channeling, upward channeling, lateral channeling, or unknown. We define downward channeling as (1) a move from a job involving contact with customers to a job without (e.g., from server to busboy), (2) a move from a white-collar position to a manual position (e.g., from sales to stocker), or (3) a move in which hierarchy is clear (e.g., from supervisor to line worker). We define upward channeling as a move in the opposite direction. We focus on these two types of channeling for our current analysis. After eliminating cases in which all testers within a team were similarly channeled, we have 23 additional cases of differential treatment that were not recorded by our initial measurement of job offers and callbacks.

Like hiring criteria, job placement is also patterned by race (see Table 1). Black applicants were channeled into lower positions in nine cases, Latinos were channeled down in five cases, and whites experienced downward channeling in only one case. Many of these cases were restaurant jobs in which the tester applied for a position as a server but was steered to a job as a busboy or dishwasher. In almost all cases, the original position required extensive customer contact while the suggested position did not (e.g., salesperson to stocker). Testers were sometimes guided into lower positions because their résumés indicated limited work experience, but racial differences in channeling suggest that insufficient work experience was more penalizing for minorities than for whites. The one case of downward channeling among white applicants involved a tester presenting with a criminal background.

In fact, whites were more often channeled up than down. In at least six cases, white testers were encouraged to apply for jobs that were of a higher-level or required more customer contact than the initial position they inquired about. In one case, the white tester was even encouraged to apply for a supervisory position, despite limited work experience. Kevin reported: "[The employer] then asked me if I had any experience in construction. I told him I did not. He asked if I would be okay working with people that have thick accents like his. I told him that was fine. He then told me that he wanted me to be his new company supervisor."

Employers appear to have strong views about what kind of person is appropriate for what kind of job, based either on their own assumptions of worker competence or assumptions about what their clients expect or prefer in the appearance of those serving them. Consistent with the testers' field notes, employers appear to apply more stringent hiring criteria to minority workers, preferring whites for jobs that require greater skill or responsibility. In addition, minorities are disproportionately channeled out of customer service positions, consistent with other research in which employers view minority applicants as lacking communication skills or as otherwise discomfiting for customers. Although our testers presented highly effective styles of interpersonal communication, the cursory review process for these jobs often leaves group membership more salient than any individuating characteristics. 
The three types of differential treatment we observe illustrate how employers enact their racial preferences in the hiring process. Rather than outward hostility or racial animus, we see more subtle forms of discouragement or rejection. At multiple points in the hiring process, black (or Latino) applicants face additional hurdles or barriers that reduce their chances of employment and affect the quality of jobs for which they are considered. Figure 3 illustrates the processes identified in the preceding discussion. At each of the three decision points, we see pathways deflected by various forms of racial bias. Subtle differences in employers' responses - often imperceptible to the applicants themselvesproduce a pattern of outcomes systematically affected by race.

Complementing the quantitative indicators of differential treatment, these qualitative observations provide a rare window into the processes by which discrimination occurs. The three categories of differential treatment observed in these data point to the range of experiences that constitute discrimination in the employment process. ${ }^{14}$ In a small number of cases, minority testers were disqualified early on in decisions that appear to reflect employers' fairly rigid preferences. These instances of categorical exclusion represent one of the most extreme forms of discrimination, wherein minority applicants have little opportunity to overcome employers' potential concerns. By contrast, a larger number of interactions suggest a more complicated set of negotiations at play. In evaluating applicant qualifications, minority applicants, and black men in particular, appear to be held to a higher standard than their white counterparts. Black men are disqualified more readily, or hired more reluctantly, than their white partners with identical skills and experience. Furthermore, racialized assessments of applicant quality and "fit" affect not only the decision to hire, but also decisions about job placement, with minority applicants more often channeled into positions involving less skill or customer contact. Together, these experiences illustrate how racial disadvantage is dynamically constructed and reinforced, with the assessment of applicant qualifications and suitability subject to interpretation and bias. While not an exhaustive catalogue of discrimination experiences, the fact that these dynamics are observed in natural settings (with little prompting) attests to their relative frequency and regularity. Our testers' experiences suggest how race shapes employers' evaluations in subtle but systematic ways, with important implications for structuring opportunity along racial lines.

\section{DISCUSSION}

Sending trained testers with equivalent résumés to apply for entry-level jobs reveals clear evidence of discrimination among low-wage employers in New York City. Blacks were only half as likely to receive a callback or job offer relative to equally qualified whites; moreover, black and Latino applicants with clean backgrounds fared no better than a white applicant just released from prison. The magnitude of these racial disparities provides vivid evidence of the continuing significance of race in contemporary low-wage labor markets. There is a racial hierarchy among young men favoring whites, then Latinos, and finally blacks as the candidates of last resort.

The episodes of discrimination recorded in this study were seldom characterized by overt racism or hostility. In fact, our testers rarely perceived any signs of clear prejudice. It was only through side-by-side comparisons of our testers' experiences that patterns of subtle but consistent differential treatment were revealed. Minority applicants were disqualified more

\footnotetext{
${ }^{14}$ To be sure, our study captures only a few of the many pathways in the employment process that are potentially affected by racial bias. Beyond our window of observation, the pathways of this diagram would presumably continue along later points in the employment process, including wage-setting decisions, training opportunities, promotion, and termination decisions. This research represents one incremental contribution to understanding - and documenting - the varied decision points that may be affected by race.
} 
readily and hired more reluctantly than their white partners with identical skills and experience. Additionally, black and Latino applicants were routinely channeled into positions requiring less customer contact and more manual work than their white counterparts. In interactions between applicants and employers, we see a small number of cases that reflect employers' seemingly rigid racial preferences. More often, differential treatment emerged in the social interaction of the job interview. Employers appeared to see more potential in the stated qualifications of white applicants, and they more commonly viewed white applicants as a better fit for more desirable jobs.

Our findings of discrimination are particularly striking because the testers in this study represent a best-case scenario for low-wage job seekers. The testers were college-educated young men with effective styles of self-presentation. Although posing as high school graduates with more limited skills, these young men stood well above the typical applicant for these low-wage jobs. The effects of race among individuals with fewer hard and soft skill advantages may well be larger than those estimated here.

At the same time, while we find robust evidence of racial discrimination, we should be careful not to interpret these results as showing the level of discrimination actively experienced by minority job seekers in the New York labor market. Our sampling design, based on employers, not workers, over-represents small firms relative to their share of employment. The sample includes many restaurants and independent retailers for whom hiring is less bureaucratic, and who lack the human resource departments that manage the equal employment opportunity obligations of large firms (Dobbin et al. 1993). Nevertheless, our sampled employers well represent the kinds of low-skill service work that dominate lowwage urban labor markets.

A second limitation on the generalizability of our findings results from our sampling procedures based on classified advertisements. Surveys of job seekers suggest that 25 to 30 percent of low skill jobs are filled by classified ads; the remainder are filled through some combination of network referrals, walk-in applications, and employment agencies (Holzer 1987). These search strategies may generate a different distribution of employers from that reported here. Some argue that the focus on jobs advertised through metropolitan newspapers understates the extent of discrimination. Firms that wish to discriminate, it is argued, are more likely to advertise job openings through more restrictive channels, such as networks of existing employees, employment agencies, or more selective publications (Elliott 2000; Fix and Struyk 1993; Petersen, Saporta, and Seidel 2000). Others, by contrast, argue that any random sample of employers will overstate the extent of discrimination actually experienced by job seekers. If minority applicants can identify and avoid firms that discriminate, the actual incidence of labor market discrimination will be correspondingly reduced (Becker 1957; Heckman 1998).

Of course, minority workers' ability to avoid the effects of discrimination by self-selecting into nondiscriminatory firms requires that a sufficient number of nondiscriminatory employers exist; that there are no differences in the quality of jobs offered by employers who are more and less likely to discriminate; and that the search costs necessary to locate nondiscriminatory employers are trivial. Future research using microdata to track the search patterns and outcomes of black and white job seekers could better address these issues. From our data, we can safely conclude that job searches across a wide range of employers represented by the classified ads of five New York newspapers reveal substantial discrimination. Understanding how job seekers adapt to this reality remains a challenge for future research. 
Our findings for the New York City labor market add to evidence of racial discrimination in employment reported from recent field experiments in Milwaukee, Boston, and Chicago (Bertrand and Mullainathan 2004; Pager 2003). The significant evidence of discrimination found in these studies contrasts sharply with recent survey research showing small racial differences in wages (Farkas and Vicknair 1996; Neal and Johnson 1996). How might these disparate findings be reconciled? First, as noted above, the presence of discrimination in the labor market may lead workers to differentially sort across employers, such that minority job seekers queue for jobs offered by employers who are less likely to discriminate. These dynamics can lead to longer search or wait times for minority job seekers, which might not be reflected in ultimate wage offers. Indeed, data from the late 1990s show that the unemployment spells of black men (3.1 months) are about twice as long as those for whites (1.6 months) (Gottschalck 2003:2). This suggests that the primary effects of discrimination on labor market outcomes may be reflected in employment differentials rather than wages. ${ }^{15}$

Second, the experience of discrimination may add to the psychic costs of the job search process, prompting some to opt out altogether. If discrimination discourages all but the most motivated and able black job seekers, black wage earners would represent an increasingly select group. Since the 1990s, increasing numbers of young black men have dropped out of the formal labor market, contributing to an artificial convergence of black and white wages (Western and Pettit 2005). Without effectively accounting for the processes that precede labor force participation-including the discouraging effects of discrimination-wage estimates can account for only one incomplete picture of the larger employment process.

Our findings add to a large research program demonstrating the continuing contribution of discrimination to racial inequality in the post-civil rights era. Still, significant questions remain unanswered. The audit experiment necessarily focuses on employers' hiring behaviors but does not examine the skills, preferences, and networks of job seekers. We do not know, and few research designs have been devised to test, the relative magnitude of the effects of discrimination compared with the effects of human and social capital. Such an analysis would need to study both employers as they screen job applicants and workers as they search for jobs.

The effects of discrimination, relative to human and social capital, should also be defined broadly. As evidence of discrimination in the post-civil rights era accumulates, new research should go beyond determining whether discrimination is present to consider how the effects of discrimination unfold over the life cycle and across social space. Episodes of discrimination may not only cause unemployment at one point in time, but may have longterm effects that weaken minority workers' attachment to the labor market and reduce labor force participation. Discrimination may produce broad cultural effects in which work itself is de-legitimated as a fair source of opportunity. The effects of discrimination may also vary across the population, concentrating perhaps among the young men whose employment rates are lowest. Tracing these larger and more varied effects of discrimination show both the advantages and limits of the experimental method used here. The experiment allows us to infer discrimination with great certainty, but the effects of discrimination are narrowly defined. The broader effects of discrimination—on the cultural dimensions of economic life and over the life course—-are harder to pinpoint but may indicate more fundamental and

\footnotetext{
15Johnson and Neal (1998), for example, find that after controlling for cognitive ability and other human capital characteristics, blackwhite differences in employment among young men remain large and statistically significant. The importance of employment over wages for racial inequality in economic status is likely to be especially great for young non-college-educated men, for whom the overall level of wage dispersion is low. Later in the life course, as wage dispersion increases and labor force experience accumulates, the racial wage gap becomes more pronounced (Tomaskovic-Devey, Thomas, and Johnson 2005). For a historical example, see Whatley (1990), who shows that despite the substantial racial barriers to employment that existed among Northern firms after World War I, blacks and whites experienced remarkably similar wage rates.
} 
intractable inequalities. A research agenda that includes these wider consequences would be less skeptical that discrimination exists and more curious about its continuing effects on not just employment inequality, but on American race relations more broadly.

\section{Acknowledgments}

This research has been supported by grants from the National Science Foundation, the National Institute of Justice, the JEHT Foundation, the Princeton Research Institute on the Region, and the Industrial Relations Section of Princeton University. The first author acknowledges generous support from NSF CAREER, NIH K01, and a W.T. Grant Scholars Award. We also gratefully acknowledge the support of the New York City Commission on Human Rights, and Commissioner Patricia Gatling. Thanks to Glenn Martin, Don Green, and the many workshop participants who provided generous feedback on earlier drafts of this article.

\section{Biographies}

Devah Pager is an Associate Professor of Sociology and Faculty Associate of the Office of Population Research at Princeton University. Her book, Marked: Race, Crime, and Finding Work in an Era of Mass Incarceration, investigates the racial and economic consequences of large scale imprisonment for contemporary U.S. labor markets.

Bruce Western is Professor of Sociology and director of the Multidisciplinary Program in Inequality and Social Policy at Harvard University.

Bart Bonikowski is a $\mathrm{PhD}$ candidate in sociology at Princeton University. In addition to his work on stratification, he is completing a project that compares popular conceptions of the nation among the populations of 30 countries.

\section{APPENDIX ROBUSTNESS CHECKS}

We examine the robustness of our primary results by looking at racial and ethnic contrasts for different subsets of the data (Table A1). Although small numbers in certain cells lead to some instability in estimates, these breakdowns can examine the consistency of effects across the full range of the sample. To account for learning or adaptation by the testers, we estimate effects for the first and second halves of the experimental period. In each period, whites and Latinos received significantly more positive responses than did blacks, and whites received slightly more positive responses than did Latinos. To examine whether our results depend strongly on any particular area within New York, we separate the experimental effects by location. Over half the audited employers were located in Manhattan. We found the pattern of black disadvantage throughout Manhattan and in the outer boroughs. To examine whether the first tester sent to an employer was more likely to be successful, we randomized the order in which testers were sent. Experimental effects are similar regardless of which tester interviewed first. Finally, we compare the outcomes of audits in which testers had little or no interaction with the employer with those characterized by more substantial personal contact. Here we see some evidence that personal contact reduces racial disparities in employment, consistent with the notion that individualizing information can help offset the effects of negative stereotypes.

The bottom half of Table A1 presents these same comparisons for the team in which the white applicants presented evidence of a felony conviction. Across these comparisons, we find treatment effects close to zero, supporting the finding that employers did not distinguish strongly between whites with criminal records and minority job seekers without. In short, these results indicate a large racial preference among New York employers for white job 
applicants over black applicants, smaller preference for whites over Latinos and Latinos over blacks, and little difference between white felons and minorities with clean backgrounds. All results are robust to tester effects and experimental effects and appear to be roughly uniform across New York City.

\section{RESULTS BY TESTER TEAMS}

In the course of fielding two three-person teams of testers, we used 10 different testers: two Latinos, four blacks, and four whites. In each three-person team consisting of a white, a black, and a Latino, we combined the 10 testers into six different unique combinations. Before pooling the data across combinations of testers, Heckman and Siegelman (1993) recommend testing for the homogeneity of responses across combinations. The columns in Table A2 represent mutually exclusive outcomes; overall response rates by race can be calculated by summing all columns in which a given race group is represented. A chi-square test within each team fails to reject the null hypothesis of homogeneity across combinations. With this evidence of homogeneity, we report treatment effects pooled across testers. Table A2 reports the detailed experimental results for each unique combination of testers.

\section{Table A1}

Percentage of Positive Responses and Race Differences, by Date, Employer Address, and Race of First Tester

\begin{tabular}{|c|c|c|c|c|c|c|c|c|c|}
\hline \multirow{3}{*}{$\frac{\text { Subsample }(\mathbf{N})}{\text { Total }(171)}$} & \multirow{3}{*}{$\begin{array}{r}\begin{array}{r}\text { White } \\
(\mathbf{W})\end{array} \\
31.0\end{array}$} & \multirow{3}{*}{$\begin{array}{r}\begin{array}{r}\text { Latino } \\
(\mathbf{L})\end{array} \\
25.1\end{array}$} & \multirow{3}{*}{$\begin{array}{r}\begin{array}{r}\text { Black } \\
\text { (B) }\end{array} \\
15.2\end{array}$} & \multicolumn{6}{|c|}{ Race Differences $^{a}$} \\
\hline & & & & \multicolumn{2}{|c|}{ W/L } & \multicolumn{2}{|c|}{ W/B } & \multicolumn{2}{|c|}{$\mathbf{L} / \mathbf{B}$} \\
\hline & & & & 1.2 & $(.02)$ & 2.0 & $(.00)$ & 1.7 & $(.00)$ \\
\hline \multicolumn{10}{|l|}{ Date $^{b}$} \\
\hline Feb. 23 to April 7 (84) & 29.8 & 23.8 & 9.5 & 1.3 & $(.08)$ & 3.1 & $(.00)$ & 2.5 & $(.00)$ \\
\hline April 8 to July 16 (84) & 33.3 & 27.4 & 21.4 & 1.2 & $(.04)$ & 1.6 & $(.00)$ & 1.3 & $(.05)$ \\
\hline \multicolumn{10}{|l|}{ Location $^{c}$} \\
\hline Below 34th St. (56) & 23.2 & 21.4 & 12.5 & 1.1 & $(.31)$ & 1.9 & $(.00)$ & 1.7 & $(.03)$ \\
\hline 34th St. to 72nd St. (46) & 30.4 & 21.7 & 17.4 & 1.4 & $(.02)$ & 1.8 & $(.00)$ & 1.3 & (.15) \\
\hline Above 72nd St. (18) & 33.3 & 22.2 & 5.6 & 1.5 & $(.00)$ & 6.0 & $(.00)$ & 4.0 & $(.00)$ \\
\hline Other (50) & 40.0 & 34.0 & 20.0 & 1.2 & (.12) & 2.0 & $(.00)$ & 1.7 & $(.00)$ \\
\hline \multicolumn{10}{|l|}{ Race of First Tester } \\
\hline White (68) & 27.9 & 23.5 & 10.3 & 1.2 & (.11) & 2.7 & $(.00)$ & 2.3 & $(.00)$ \\
\hline Black (45) & 40.0 & 31.1 & 20.0 & 1.3 & $(.06)$ & 2.0 & $(.00)$ & 1.6 & $(.01)$ \\
\hline Latino (53) & 28.3 & 22.6 & 18.9 & 1.3 & (.09) & 1.5 & $(.00)$ & 1.2 & (.15) \\
\hline \multicolumn{10}{|l|}{ Type of Positive Response ${ }^{d}$} \\
\hline Callback (171) & 12.9 & 9.9 & 2.9 & 1.3 & (.10) & 4.4 & $(.00)$ & 3.4 & $(.00)$ \\
\hline Job offer (171) & 21.1 & 17.0 & 12.9 & 1.2 & $(.02)$ & 1.6 & $(.00)$ & 1.3 & $(.02)$ \\
\hline \multicolumn{10}{|l|}{ Personal Contact ${ }^{e}$} \\
\hline No personal contact $(46)^{f}$ & 10.9 & 6.5 & 0 & 1.7 & (.09) & $>10.9$ & & $>6.5$ & \\
\hline \multirow[t]{2}{*}{ Personal contact (65) } & 52.3 & 46.2 & 29.2 & 1.1 & (.11) & 1.8 & $(.00)$ & 1.6 & $(.00)$ \\
\hline & & & & \multicolumn{6}{|c|}{ Race Differences $^{a}$} \\
\hline Subsample (N) & $\begin{array}{r}\text { White felon } \\
\text { (Wf) }\end{array}$ & $\begin{array}{r}\text { Latino } \\
\text { (L) }\end{array}$ & $\begin{array}{r}\text { Black } \\
\text { (B) }\end{array}$ & & $\mathrm{f} / \mathrm{L}$ & W & & & B \\
\hline
\end{tabular}




\begin{tabular}{|c|c|c|c|c|c|c|c|c|c|}
\hline \multirow{3}{*}{$\frac{\text { Subsample }(\mathbf{N})}{\text { Total (169) }}$} & \multirow{3}{*}{$\begin{array}{r}\begin{array}{r}\text { White } \\
\text { (W) }\end{array} \\
17.2\end{array}$} & \multirow{3}{*}{$\begin{array}{r}\begin{array}{r}\text { Latino } \\
(\mathbf{L})\end{array} \\
15.4\end{array}$} & \multirow{3}{*}{$\begin{array}{r}\begin{array}{r}\text { Black } \\
(\mathbf{B})\end{array} \\
13.0\end{array}$} & \multicolumn{6}{|c|}{ Race Differences $^{a}$} \\
\hline & & & & \multicolumn{2}{|c|}{ W/L } & \multicolumn{2}{|c|}{ W/B } & \multicolumn{2}{|c|}{$\mathbf{L} / \mathbf{B}$} \\
\hline & & & & 1.1 & $(.25)$ & 1.3 & $(.08)$ & 1.2 & $(.17)$ \\
\hline \multicolumn{10}{|l|}{ Date $^{b}$} \\
\hline March 2 to April 13 (83) & 16.9 & 13.3 & 10.8 & 1.3 & $(.16)$ & 1.6 & $(.06)$ & 1.2 & $(.21)$ \\
\hline April 14 to Aug. 6 (82) & 17.1 & 17.1 & 15.9 & 1.0 & (.43) & 1.1 & (.35) & 1.1 & $(.34)$ \\
\hline \multicolumn{10}{|l|}{ Location $^{c}$} \\
\hline Below 34th St. (51) & 9.8 & 7.8 & 3.9 & 1.3 & $(.30)$ & 2.5 & $(.05)$ & 2.0 & $(.00)$ \\
\hline 34th St. to 72nd St. (46) & 13.0 & 17.4 & 13.0 & .8 & $(.74)$ & 1.0 & $(.42)$ & 1.3 & $(.14)$ \\
\hline Above 72nd St. (7) & 0 & 0 & 0 & & & & & & \\
\hline Other (62) & 29.0 & 21.0 & 21.0 & 1.4 & $(.08)$ & 1.4 & $(.09)$ & 1.0 & (.46) \\
\hline \multicolumn{10}{|l|}{ Race of First Tester } \\
\hline White (53) & 20.8 & 18.9 & 13.2 & 1.1 & $(.34)$ & 1.6 & (.13) & 1.4 & (.15) \\
\hline Black (59) & 18.6 & 15.3 & 15.3 & 1.2 & $(.20)$ & 1.2 & $(.15)$ & 1.0 & $(.39)$ \\
\hline Latino (52) & 11.5 & 11.5 & 11.5 & 1.0 & $(.44)$ & 1.0 & $(.42)$ & 1.0 & $(.41)$ \\
\hline \multicolumn{10}{|l|}{ Type of Positive Response ${ }^{d}$} \\
\hline Callback (169) & 11.2 & 9.5 & 5.3 & 1.2 & $(.23)$ & 2.1 & $(.01)$ & 1.8 & $(.02)$ \\
\hline Job offer (169) & 5.9 & 6.5 & 7.7 & .9 & $(.58)$ & .8 & $(.77)$ & .8 & $(.65)$ \\
\hline \multicolumn{10}{|l|}{ Personal Contact $e$} \\
\hline No personal contact (75) & 8.0 & 8.0 & 4.0 & 1.0 & $(.45)$ & 2.0 & $(.09)$ & 2.0 & $(.04)$ \\
\hline Personal contact (39) & 35.9 & 28.2 & 30.8 & 1.3 & $(.12)$ & 1.2 & $(.24)$ & .9 & $(.58)$ \\
\hline
\end{tabular}

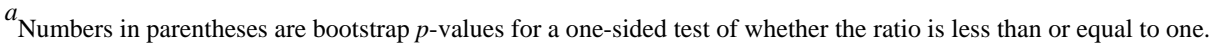

${ }^{b}$ Changes over time capture several possible effects: learning or adaptation by testers, compositional changes in the types of employers brought into the sample at different points, and changes in the business cycle.

${ }^{c}$ Street addresses are for Manhattan.

$d_{\text {Because some testers received both a job offer and a subsequent callback, the sum of these two columns may be greater }}$ than the total listed above (in which a positive response is calculated by the presence of a callback or a job offer).

$e^{e}$ Analyses of "personal contact" include only those cases in which all tester partners experienced personal contact; the "no personal contact" analyses include cases in which none of the testers experienced personal contact. This exclusion avoids any confounding effect of employers' racial preferences as reflected in the decision to interview.

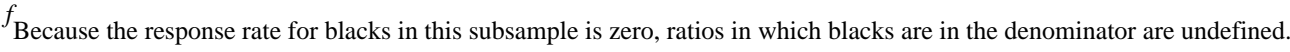
For the purposes of this analysis, we represent this ratio as greater than the value of the numerator over one.

\section{Table A2}

Detailed Experimental Results, by Unique Combination of Testers

\begin{tabular}{|c|c|c|c|c|c|c|c|c|c|}
\hline \multirow[b]{2}{*}{ Group } & \multicolumn{8}{|c|}{ Who Gets a Positive Response (percent) } & \multirow[b]{2}{*}{$\mathbf{N}$} \\
\hline & All & None & $\mathbf{W}+\mathbf{L}$ & $\mathbf{W}+\mathbf{B}$ & $\mathbf{L}+\mathbf{B}$ & $\mathbf{W}$ & $\mathbf{L}$ & B & \\
\hline \multicolumn{10}{|c|}{ White without criminal record (posterior predictive probability of $\chi^{2}$ statistic: .054$)^{a}$} \\
\hline 1 & 11 & 69.2 & 4.4 & 3.3 & 0 & 7.7 & 4.4 & 0 & 91 \\
\hline 2 & 7.5 & 67.9 & 11.3 & 0 & 0 & 9.4 & 3.8 & 0 & 53 \\
\hline 3 & 36.4 & 18.2 & 0 & 0 & 0 & 18.2 & 18.2 & 9.1 & 11 \\
\hline 4 & 33.3 & 33.3 & 33.3 & 0 & 0 & 0 & 0 & 0 & 6 \\
\hline 5 & 28.6 & 57.1 & 14.3 & 0 & 0 & 0 & 0 & 0 & 7 \\
\hline
\end{tabular}




\begin{tabular}{llllllllllr}
\hline & \multicolumn{7}{c}{ Who Gets a Positive Response (percent) } & \\
\cline { 2 - 7 } Group & All & None & W + L & W + B & L + B & W & L & B & N \\
\hline 6 & 0 & 66.7 & 0 & 0 & 0 & 33.3 & 0 & 0 & 3 \\
Total & 12.9 & 63.7 & 7.6 & 1.8 & 0 & 8.8 & 4.7 & .6 & 171 \\
\multicolumn{6}{l}{ White with criminal record (posterior predictive probability of $\chi^{2}$} & statistic: .588) \\
1 & 3.7 & 75.3 & 2.5 & 2.5 & 1.2 & 7.4 & 4.9 & 2.5 & 81 \\
2 & 4.9 & 56.1 & 2.4 & 2.4 & 7.3 & 14.6 & 7.3 & 4.9 & 41 \\
3 & 2.8 & 77.8 & 8.3 & 2.8 & 2.8 & 2.8 & 0 & 2.8 & 36 \\
4 & 0 & 60 & 0 & 0 & 20 & 0 & 20 & 0 & 5 \\
5 & 0 & 75 & 0 & 0 & 0 & 0 & 0 & 25 & 4 \\
6 & 0 & 100 & 0 & 0 & 0 & 0 & 0 & 0 & 2 \\
Total & 3.6 & 71.0 & 3.6 & 2.4 & 3.6 & 7.7 & 4.7 & 3.6 & 169 \\
\hline
\end{tabular}

Note: $\mathrm{W}=$ white; $\mathrm{L}=$ Latino; $\mathrm{B}=$ black. Columns of "Who Gets a Positive Response" represent mutually exclusive categories (i.e., rows sum to 100 percent). In the first experiment (no criminal record), there was only a single case (group 3 ) in which a black tester received a callback when neither of his test partners received one.

${ }^{a}$ The chi-square test is undefined with marginal counts of zero. We calculate a posterior predictive $p$-value by simulating counts under independence for nonzero cells.

\section{REFERENCES}

Agresti, Alan. Categorical Data Analysis. New York: Wiley; 1990.

Aigner, Dennis J.; Cain, Glen G. Statistical Theories of Discrimination in Labor Market. Industrial and Labor Relations Review 1977;30:749-776.

Altonji, Joseph G.; Pierret, Charles R. Employer Learning and Statistical Discrimination. Journal of Economics 2001;116:313-350.

Becker, Gary S. The Economics of Discrimination. Chicago, IL: University of Chicago Press; 1957.

Bendick, Marc, Jr; Charles, Jackson; Reinoso, Victor. Measuring Employment Discrimination through Controlled Experiments. Review of Black Political Economy 1994;23:25-48.

Bendick, Marc, Jr; Charles, Jackson; Victor, Reinoso; Hodges, Laura. Discrimination against Latino Job Applicants: A Controlled Experiment. Human Resource Management 1991;30:469-484.

Bertrand, Marianne; Mullainathan, Sendhil. Are Emily and Greg More Employable than Lakisha and Jamal? A Field Experiment on Labor Market Discrimination. American Economic Review 2004;94:991-1013.

Biernat, Monica; Kobrynowicz, Diane D. Gender and Race-Based Standards of Competence: Lower Minimum Standards but Higher Ability Standards for Devalued Groups. Journal of Personality and Social Psychology 1997;72:544-557. [PubMed: 9120783]

Bodenhausen, Galen. Stereotypic Biases in Social Decision Making and Memory: Testing Process Models of Stereotype Use. Journal of Personality and Social Psychology 1988;55(5):726-737. [PubMed: 3210142]

Cancio, A Silvia; Evans, T David; Maume, David J. Reconsidering the Declining Significance of Race: Racial Differences in Early Career Wages. American Sociological Review 1996;61:541556.

Cross, Harry; Genevieve, Kenney; Jane, Mell; Zimmerman, Wendy. Employer Hiring Practices: Differential Treatment of Hispanic and Anglo Job Seekers. Washington, DC: Urban Institute Press; 1990.

Darity, William, Jr; Mason, Patrick A. Evidence on Discrimination in Employment: Codes of Color, Codes of Gender. The Journal of Economic Perspectives 1998;12:63-90.

Darity, William, Jr; Meyers, Samuel L. Persistent Disparity: Race and Economic Inequality in the United States since 1945. Cheltenham, UK: Edward Elgar; 1998. 
Darley, John M.; Gross, Paget H. A Hypothesis-Confirming Bias in Labeling Effects. Journal of Personality and Social Psychology 1983;44:20-33.

Dobbin, Frank J.; Sutton, J Meyer; Scott, WR. Equal Opportunity Law and the Construction of Internal Labor Markets. American Journal of Sociology 1993;99:396-427.

Dovidio, John F.; Gaertner, Samuel L. Aversive Racism and Selection Decisions. Psychological Science 2000;11:315-319. [PubMed: 11273391]

Elliott, James R. Class, Race, and Job Matching in Contemporary Urban Labor Markets. Social Science Quarterly 2000;81:1036-1052.

Farkas, George; Vicknair, Keven. Appropriate Tests of Racial Wage Discrimination Require Controls for Cognitive Skill: Comment on Cancio, Evans, and Maume. American Sociological Review 1996;61:557-560.

Fiske, Susan. Stereotyping, Prejudice, and Discrimination. In: Gilbert, D.; Fiske, S.; Lindzey, G., editors. The Handbook of Social Psychology. Boston, MA: McGraw Hill; 1998. p. 357-411.

Fix, Michael; Struyk, Raymond J., editors. Clear and Convincing Evidence: Measurement of Discrimination in America. Washington, DC: Urban Institute Press; 1993.

Fryer, Ronald G., Jr; Levitt, Steven D. NBER Working Paper; 2003. The Causes and Consequences of Distinctively Black Names; p. 9938

Fryer, Ronald G., Jr; Levitt, Steven D. The Causes and Consequences of Distinctively Black Names. The Quarterly Journal of Economics 2004;119:767-805.

Ghosh, Malay; Ming-Hui, Chen; Atalanta, Ghosh; Agresti, Alan. Hierarchical Bayesian Analysis of Binary Matched Pairs Data. Statistica Sinica 2000;10:647-657.

Gilbert, Daniel T.; Hixon, J Gregory. The Trouble of Thinking: Activation and Application of Stereotypical Beliefs. Journal of Personality and Social Psychology 1991;60(4):509-517.

Gottschalck, Alfred O. Current Population Reports. Washington, DC: US Census Bureau; 2003. Dynamics of Economic Well-Being: Spells of Unemployment, 1996-1999.

Heckman, James J. Detecting Discrimination. The Journal of Economic Perspectives 1998;12:101116.

Heckman, James; Siegelman, Peter. The Urban Institute Audit Studies: Their Methods and Findings. In: Fix, M.; Struyk, R., editors. Clear and Convincing Evidence: Measurement of Discrimination in America. Lanham, MD: University Press of America; 1993. p. 187-258.

Holzer, Harry J. Informal Job Search and Black Youth Unemployment. American Economic Review 1987;77:446-452.

Holzer, Harry J. What Employers Want: Job Prospects of Less-Educated Workers. New York: Russell Sage Foundation; 1996.

Holzer, Harry J.; Offner, Paul. Washington, DC: Georgetown University; 2001. Trends in Employment Outcomes of Young Black Men. Unpublished manuscript

Johnson, William; Neal, Derek. Basic Skills and the Black-White Earnings Gap. In: Jencks, C.; Phillips, M., editors. Black-White Test Score Differences. Washington, DC: Brookings Institution; 1998. p. 480-500.

Kirschenman, Joleen; Neckerman, Katherine. 'We'd Love to Hire Them, but...': The Meaning of Race for Employers. In: Jencks, C.; Peterson, P., editors. The Urban Underclass. Washington, DC: Brookings Institute; 1991. p. 203-234.

Moss, Philip; Tilly, Chris. Stories Employers Tell: Race, Skill, and Hiring in America. New York: Russell Sage; 2001.

Neal, Derek; Johnson, William. The Role of Premarket Factors in Black-White Wage Differences. Journal of Political Economy 1996;104:869-895.

Oettinger, Gerald S. Statistical Discrimination and the Early Career Evolution of the Black-White Wage Gap. Journal of Labor Economics 1996;14:52-78.

O'Neill, June. The Role of Human Capital in Earnings Differences between White and Black Men. The Journal of Economic Perspectives 1990;4(4):25-45.

Pager, Devah. The Mark of a Criminal Record. American Journal of Sociology 2003;108:937-975. 
Pager, Devah. The Use of Field Experiments for Studies of Employment Discrimination:

Contributions, Critiques, and Directions for the Future. Annals of the American Academy of Political and Social Sciences 2007a;609:104-133.

Pager, Devah. Marked: Race, Crime, and Finding Work in an Era of Mass Incarceration. Chicago, IL: University of Chicago Press; 2007b.

Pager, Devah; Karafin, Diana. Bayesian Bigot? Statistical Discrimination, Stereotypes, and Employer Decision-Making. Annals of the American Academy of Political and Social Science 2009;621(1): 70-93.

Pager, Devah; Quillian, Lincoln. Walking the Talk: What Employers Say Versus What They Do. American Sociological Review 2005;70(3):355-380.

Petersen, Trond; Ishak, Saporta; Seidel, Marc-David L. Offering a Job: Meritocracy and Social Networks. American Journal of Sociology 2000;106:763-816.

Pettit, Becky; Western, Bruce. Mass Imprisonment and the Life Course: Race and Class Inequality in U.S. Incarceration. American Sociological Review 2004;59:151-169.

Roscigno, Vincent J.; Lisette, Garcia; Sherry, Mong; Byron, Reginald. Racial Discrimination at Work: Its Occurrence, Dimensions, and Consequences. The New Black: Alternative Paradigms and Strategies for the 21st Century Research in Race and Ethnic Relations 2007;14:131-155.

Steele, Claude M.; Aronson, Joshua. Stereotype Threat and the Intellectual Test Performance of African Americans. Journal of Personality and Social Psychology 1995;69(5):797-811. [PubMed: 7473032]

Tomaskovic-Devey, Donald; Melvin, Thomas; Johnson, Kecia. Race and the Accumulation of Human Capital across the Career: A Theoretical Model and Fixed-Effects Application. American Journal of Sociology 2005;111(1):58-89.

Trope, Yaacov; Thomson, Erik P. Looking for Truth in All the Wrong Places? Asymmetric Search of Individuating Information about Stereotyped Group Members. Journal of Personality and Social Psychology 1997;73(2):229-441. [PubMed: 9248047]

Turner, Margery; Michael, Fix; Struyk, Raymond. Opportunities Denied, Opportunities Diminished: Racial Discrimination in Hiring. Washington, DC: Urban Institute Press; 1991.

Waldinger, Roger; Lichter, Michael I. How the Other Half Works: Immigration and the Social Organization of Labor. Berkeley, CA: University of California Press; 2003.

Western, Bruce; Pettit, Becky. Black-White Wage Inequality, Employment Rates, and Incarceration. American Journal of Sociology 2005;111:553-578.

Whatley, Warren C. Getting a Foot in the Door: 'Learning,' State Dependence, and the Racial Integration of Firms. The Journal of Economic History 1990;50(1):43-66.

Wilson, William Julius. When Work Disappears: The World of the New Urban Poor. New York: Vintage Books; 1996.

Yarkin KL, Town JP, Wallston BS. Blacks and Women Must Try Harder: Stimulus Person's Race and Sex Attributions of Causality. Personality and Social Psychology Bulletin 1982;8:21-24. 


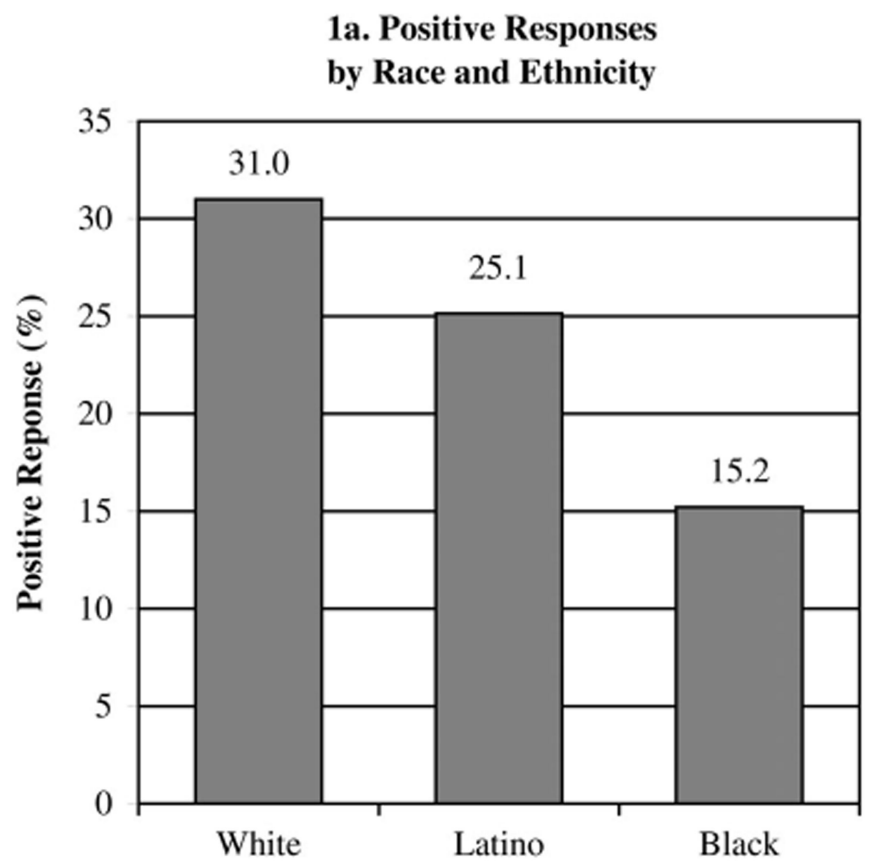

1b. Ratios of Positive Responses by Race and Ethnicity

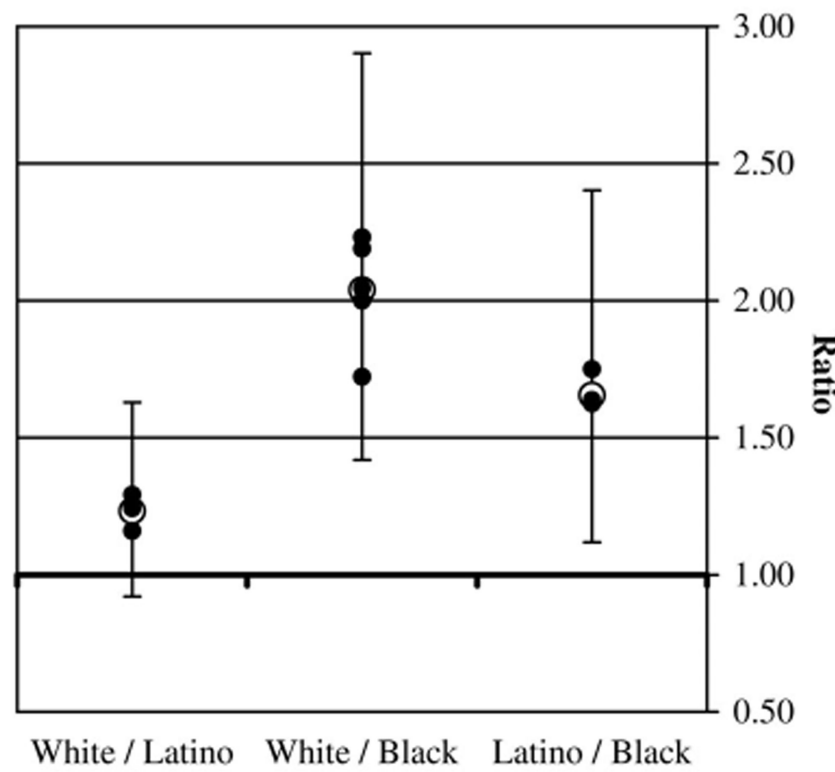

Figure 1.

Positive Response Rates and Paired Comparisons by Race and Ethnicity

Notes:Positive responses refer to callbacks or job offers. Hollow circles in Figure $1 \mathrm{~b}$ indicate point estimates of the ratio. Solid circles indicate ratios obtained by sequentially dropping testers from the analysis. We estimated 95 percent confidence intervals from a hierarchical logistic regression with employer and tester random effects. Number of employers $=171$. 


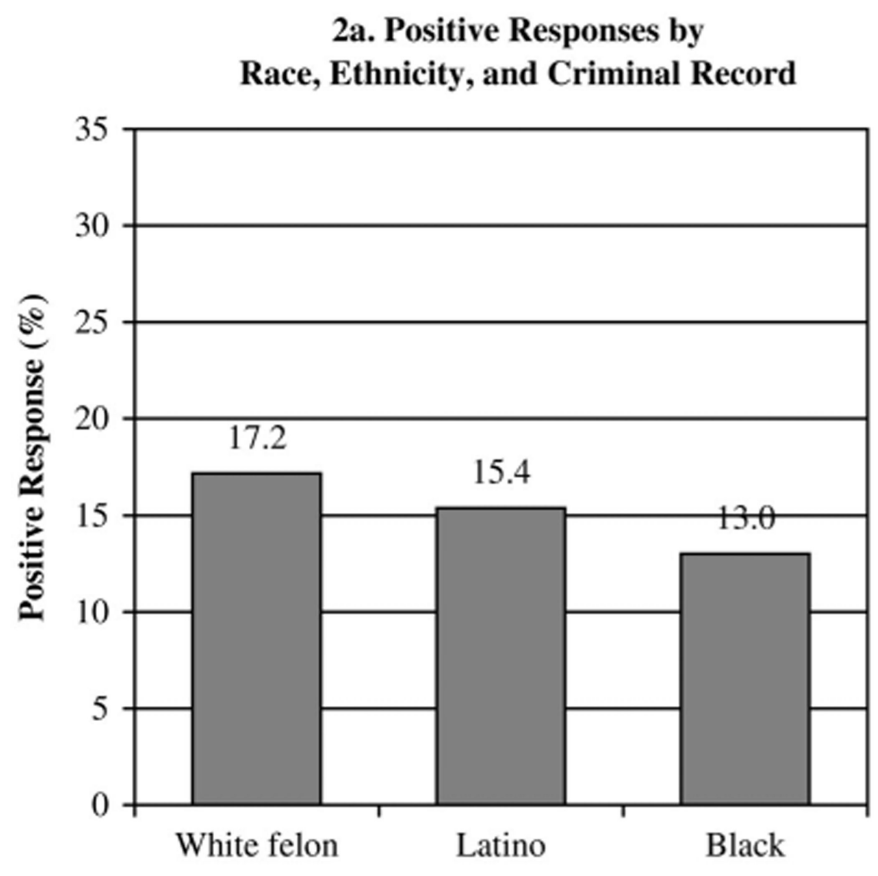

\section{2b. Ratios of Positive Responses by Race, Ethnicity, and Criminal Record}

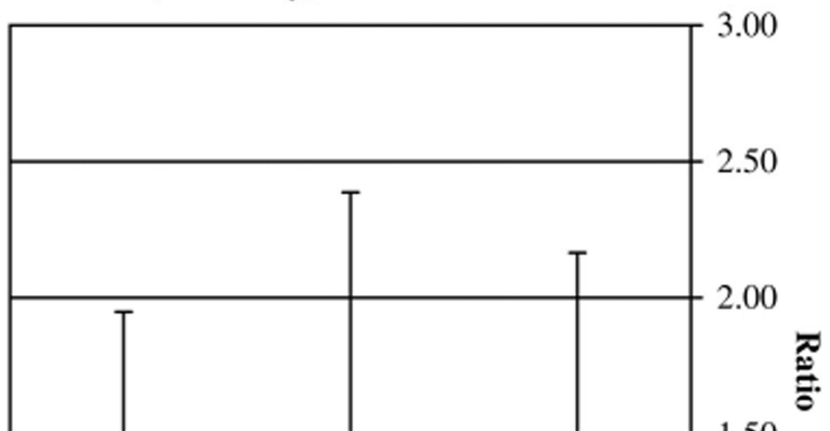

Figure 2.

Positive Response Rates and Paired Comparisons by Race, Ethnicity, and Criminal Background

Notes: Positive responses refer to callbacks or job offers. Hollow circles in Figure $2 \mathrm{~b}$ indicate point estimates of the ratio. Solid circles indicate ratios obtained by sequentially dropping testers from the analysis. We estimated 95 percent confidence intervals from a hierarchical logistic regression with employer and tester random effects. Number of employers $=169$. 
Initial Point of Contact

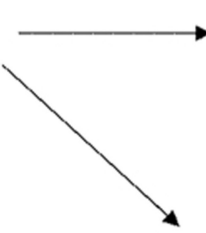

Categorical

Exclusion
Assessment of Qualifications

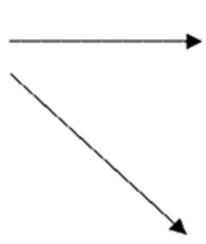

Shifting

Standards
Job

Placement

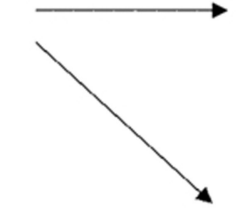

Channeling

Figure 3.

Discrimination at Three Decision Points 


\section{Table 1}

Job Channeling by Race

\begin{tabular}{|c|c|}
\hline Original Job Title & Suggested Job \\
\hline \multicolumn{2}{|c|}{ Blacks Channeled Down } \\
\hline Server & Busser \\
\hline Counter person & Dishwasher/porter \\
\hline Server & Busboy \\
\hline Assistant manager & Entry fast-food position \\
\hline Server & Busboy/runner \\
\hline Retail sales & Maintenance \\
\hline Counter person & Delivery \\
\hline Sales & Stockboy \\
\hline Sales & Not specified ${ }^{a}$ \\
\hline \multicolumn{2}{|c|}{ Latinos Channeled Down } \\
\hline Server & Runner \\
\hline Sales & Stock \\
\hline Steam cleaning & Exterminator \\
\hline Counter person & Delivery \\
\hline Sales & Stock person \\
\hline \multicolumn{2}{|c|}{ Whites Channeled Down } \\
\hline Server & Busboy \\
\hline \multicolumn{2}{|l|}{ Latinos Channeled Up } \\
\hline Carwash attendant & Manager \\
\hline Warehouse worker & Computer/office \\
\hline \multicolumn{2}{|l|}{ Whites Channeled Up } \\
\hline Line cook & Waitstaff \\
\hline Mover & Office/telesales \\
\hline Dishwasher & Waitstaff \\
\hline Driver & Auto detailing \\
\hline Kitchen job & "Front of the house" job \\
\hline Receptionist & Company supervisor \\
\hline
\end{tabular}

Note: This table includes all cases of upward and downward channeling, except when all testers on a team were channeled similarly.

amployer told tester that "sales might not be right for you." 